\title{
Comparative Antimicrobial Efficacy Evaluation of Aqueous and Alcoholic Extracts of Ayurvedic Vaginal Formulation for Treatment of Vaginitis
}

\author{
Mradu Gupta ${ }^{1}$, Simit Kumar², Benoy Brata Bhowmik ${ }^{3}$, \\ Nandita Karmakar ${ }^{1}$ and Saswati Sasmal ${ }^{1}$
}

\author{
${ }^{1}$ Institute of Post Graduate Ayurvedic Education and Research, 294/3/1, A. P. C. Road, \\ Kolkata, India - 700009, India \\ ${ }^{2}$ Department of Microbiology, R. G. Kar Medical College \& Hospital, \\ Kolkata - 700004, India \\ ${ }^{3}$ Dr. B. C. Roy College of Pharmacy and Allied Health Sciences, Durgapur, \\ WB -713206, India \\ *Corresponding author
}

\section{Keywords}

Antimicrobial, Medicinal plant, Minimum inhibitory concentration, Agar dilution method

Article Info

Accepted:

07 March 2019

Available Online:

10 April 2019

\section{A B S T R A C T}

This in-vitro study evaluates the antibacterial \&antifungal action of aqueous \& alcoholic extracts of new herbal vaginal formulation containing equal amounts of Symplocos racemosa Roxb. and Ficus glomerata Roxb. stem barks against gram positive and gram negative bacteria and candid fungus by using the methods of zone of inhibition and minimum inhibition concentration (MIC) to assess its efficacy in treating vaginitis. During phytochemical analysis, alkaloids, flavonoids, tannins and carbohydrates were found to be present in both extracts. Total phenol content (TPC) determined using the Folin- Ciocalteu reagent was found to be 225.67 and $220.00 \mu \mathrm{g}$ Gallic acid equivalent/mg in the aqueous and alcoholic extract respectively. The results of minimum inhibition concentration study suggest higher antimicrobial activity by the alcoholic extract than the aqueous extract and more pronounced antibacterial action than the anti-fungal action by both extracts. The MIC values were also higher in case of fungal species as compared to all the bacterial species, while among the bacterial species, MIC was found to be higher in case of gram negative bacteria than gram positive bacteria except Staphylococcus aureus. Determination of the diameter of zone of inhibition during disk diffusion study suggested higher antibacterial action than anti-fungal action, and stronger antibacterial effect upon Gram positive bacteria than Gram negative bacteria by all extracts. The alcoholic extract exhibited higher zones of inhibition than aqueous extract for all antimicrobial categories. Similarly, antimicrobial efficacy of alcoholic extract using $8 \mathrm{mg}$ per disk drug dosage was a little lower but comparable to effect of the standard drugs at $10 \mu \mathrm{g} / \mathrm{disc}$ level. The overall antimicrobial effect of the research extracts was significant and comparable but a little lower when compared to the standard drugs. 


\section{Introduction}

Herbal medicines have been known to mankind for several centuries. The World Health Organization estimates that plant extracts or their active constituents are used as folk medicine in traditional therapies of $80 \%$ of the world's population (Farnsworth et al., 1985).Plants and other natural sources can provide a huge range of complex and structurally diverse compounds. Most plants are rich in a wide variety of secondary metabolites such as tannins, terpenoids, alkaloids, flavonoids, glycosides, etc., which have been found in vitro to have antimicrobial properties (Hegde et al., 2008; Wang and Jiao, 2000; Zivkovic et al., 2010).

In fact, antimicrobial properties of medicinal plants are being increasingly reported from different parts of the world. Recently, many researchers have focused on the investigation of plant and microbial extracts, essential oils, pure secondary metabolites and new synthetized molecules as potential antimicrobial agents (Wei et al., 2006; Jain et al., 2008; Doughari et al., 2008; Akinpelu and Onakoyo, 2006; Bhalodia and Shukla, 2011). Since the problem of microbial resistance is growing, efforts are needed to control the use of antibiotics, develop research to better understand the genetic mechanisms of resistance, and to continue studies to develop new appropriate and efficient antimicrobial drugs.

Vaginitis is a general term for inflammation of the vagina and vulva. A change in the normal balance of vaginal bacteria or vaginal infections usually causes vaginitis. The most common types of vaginitis are bacterial vaginosis, yeast infections, trichomoniasis and vaginal atrophy (atrophic vaginitis). Although the symptoms of vaginitis may vary depending upon the cause, common symptoms include vaginal itching, abnormal vaginal discharge with an unpleasant odor, pain or burning during urination, discomfort during intercourse and vaginal bleeding or spotting.

The research formulation has been newly prepared by adding equal amounts of dried parts of the stem bark of Ficus glomerata Roxb. and Symplocos racemosa Roxb. because these two plants have been used since ancient times in the Ayurvedic system of medicine and elaborated in ancient texts such as CharakSamhita (Chikitsa Sthanam) as an astringent, haemostatic and anti-inflammatory substance and for arresting excessive abnormal vaginal discharge in the form of single drug and in combined polyherbal form(Shastri, 1988). This is a new herbal formulation which has not been evaluated till now although it is likely to exhibit sustained and significant antimicrobial action due to the synergetic effect of the phenolic and flavonoidic compounds present in this research drug and the pharmacological properties of its constituent herbs.

Ficus glomerata Roxb. or Cluster Fig which belongs to the Moraceae family is a moderate sized spreading lactiferous tree without much prominent aerial roots found throughout India and its fruits are eaten by villagers. Its leaves are dark green, ovate or elliptical while the fruits contain receptacles $2-5 \mathrm{~cm}$. in diameter, subglobose, smooth. When ripe, the fruits are orange, dull reddish and having pleasant smell. The stem bark is grayish green, soft surface and uneven $0.5-1.8 \mathrm{~cm}$. thick. On rubbing it, white papery flakes come out from the outer surface; the inner surface is light brown, fracture fibrous, taste mucilaginous.

The stem bark, fruits, leaves and latex of this plant have been used since ancient time as mentioned in the Ayurvedic text book for treatment of dysentery, diarrhoea, astringent, toothache, wound healing, stomach-ache, 
vaginal disorders, menorrhagia, haemoptysis, diabetes, piles and glandular swelling, etc. The roots of the plant are used in dysentery, pectoral complications, and diabetes, and also applied in inflammatory glandular enlargement, mumps, and hydrophobia. The latex is externally applied on wounds to decrease inflammation, pain, and edema, and promote its healing. The Phytochemical compounds isolated from the stem bark are leucocyanidin-3-o-B-glucopyranoside,

leucopelarogonidin 3-O-a- L-
rhamnopyranoside, B- sitosterol, stigmasterol, tetracyclic triterpene- gluanol acetate and tiglic acid. The reported pharmacological properties of the different plant parts are hypoglycemic, antiulcer, antioxidant, woundhealing, anti-inflammatory, anti-diarrhoeal, antibacterial, antifungal, antipyretic and antidiuretic(Shastri, 1988; Sharma, 1995; Sharma et al., 2001; Joshi and Mohini, 2008).

Symplocos racemosa Roxb. known as Lodhra belonging to the family Symplocaceae is distributed throughout North Eastern India, up to 2,500 $\mathrm{ft}$., it is a small evergreen tree with stem up to $6 \mathrm{~m}$ height and $15 \mathrm{~cm}$ in diameter. The leaves are dark green above, orbicular, elliptic oblong, coriaceous and glabrous above; the flowers are white, turning yellow, fragrant, in axillary, simple or compound racemes; the drupes are purplish black, subcylindric, smooth and 1-3 seeded. Its stem Bark is useful in bowel complaints such as diarrhea, dysentery, in dropsy, eye disease, liver complaints, wound healing, excessive vaginal discharge, menstrual problems, fevers, ulcers, scorpion-string, etc. The bark is often employed in the preparation of plasters and is supposed to promote maturation or resolution of stagnant tumors. A decoction of the bark or wood is used as gargle for giving firmness to spongy and bleeding gums and relaxed uvula. It is one of the constituents of a plaster used to promote maturation of boils and other malignant growths (Shastri, 1988; Sharma, 1995; Sharma et al., 2001).
The phytochemical investigation of the nbutanol soluble fraction of the bark of stem of Symplocos racemosa Roxb. yield two phenolic glycosides of salirepin series namely symplocuronic acid and sympocemoside while salirepin has also been isolated from this plant. The alcohol extract of stem bark indicated the presence of carbohydrate, glycoside, saponin and terpenoid \& alkaloid and ether extract indicated the presence of glycoside, phytosterol and steroid. The pharmacological activities of its stem bark are antibacterial, anti-inflammatory, antiulcer, anti-tumor, antimicrobial and antioxidant (Devmurari, 2010; Ahmad et al., 2003).

The objective of this in-vitro study is to find out the antibacterial and antifungal action of the aqueous and alcoholic extracts of the new herbal vaginal formulation having equal amounts of Symplocos racemosa Roxb. And Ficus glomerata Roxb stem barks against common microbes including gram positive and gram negative bacteria and candid fungus by using the in-vitro methods of zone of inhibition and MIC (minimum inhibition concentration) since the main cause of vaginitis is action of different types microbes on the vagina and vulva of human subjects.

\section{Materials and Methods}

\section{Plant sample collection}

The stem barks of Symplocos racemosa Roxb. And Ficus glomerata Roxb. were purchased from crude drug supplier of Katwa Chowrasta, Burdwan district and plant samples were authenticated by the Botanical Survey of India, Howrah, India (Ref. No. BSI/CNH/SF/Tech./2016). Both authenticated specimen vis IPGAE\&R/Dravyaguna/ M.Gupta/07 and IPGAE\&R/Dravyaguna/ M.Gupta/08 were deposited in the form of herbarium in the museum of the department of Dravyaguna at I.P.G.A.E.\&R., Kolkata for future reference. 


\section{Chemicals}

The chemicals for analysis were purchased from standard companies, e.g., Tetracycline $10 \mu \mathrm{g} / \mathrm{disc}$ from M/s HIMEDIA (Lot No.0000240795), Clotrimazole 10 $\mu \mathrm{g} / \mathrm{disc}$ from M/s HIMEDIA (Lot No.0000237894). Beef extract, Yeast extract, Malt extract, Glucose and Agar were purchased from M/s Merck while Peptone was procured from NICE Chemicals (P) Ltd.

\section{Organisms collection}

The following organisms were collected from Microbial Type Culture Collection and Gene Bank (MTCC), Chandigarh for antimicrobial activity;

\section{Gram positive bacteria}

Staphylococcus aureus(MTCC 7405)

Lactobacillus fermentum(MTCC 1745)

\section{Gram-negative bacteria}

Echerchia coli (MTCC 1575)

Salmonella enterica(MTCC 1164)

\section{Fungi}

\section{Candida albican(MTCC 3958)}

\section{Plant material extraction}

The stem barks of Symplocos racemosa Roxb. And Ficus glomerata Roxb were thoroughly washed, air-dried and pre-heated in oven before being powdered in a grinding machine to 40 \# mesh particle size. The research formulation was prepared by mixing equal amounts of stem bark powder of both the plants and sieving it before storage in an airtight container. This coarse powder was sequentially extracted with petroleum ether $\left(60^{\circ} \mathrm{C}-80^{\circ} \mathrm{C}\right)$, chloroform, acetone, ethanol and water using Soxhlet apparatus. These extracts were filtered using a Buckner funnel and Whatman No. 1 filter paper at room temperature and concentrated at reduced temperature and pressure using rotary evaporator. All obtained extracts were stored in refrigerator below $10^{\circ} \mathrm{C}$ for subsequent experiments. In this study, the aqueous and alcoholic (ethanol) extracts of the herbal vaginal formulation were evaluated for its antimicrobial activity (Furniss et al., 1989; Harborne, 1984).

\section{Preliminary phytochemical screening}

The extracts were subjected to preliminary phytochemical testing to detect the presence of different groups of chemical compounds such as saponins, tannins, alkaloids, flavonoids, glycosides, carbohydrates, oils and fats, proteins and amino acids following the standard methods described in Ayurvedic pharmacopeia.

\section{Total phenol content}

Total phenol content (TPC) was determined using the Folin- Ciocalteu reagent. To $0.5 \mathrm{ml}$ aliquot of dried aqueous extract, $2.5 \mathrm{ml}$ of 10 $\%$ Folin- Ciocalteu's reagent and $2 \mathrm{ml}$ of $7.5 \%$ sodium carbonate were added. The absorbance was read after $30 \mathrm{~min}$ incubation period at room temperature at $760 \mathrm{~nm}$ colorimetrically. A standard calibration plot was generated at $760 \mathrm{~nm}$ using different concentrations of Gallic acid (100, 200, 300, 400 , and $500 \mu \mathrm{g} / \mathrm{ml})$. The concentration of phenol in the test samples was calculated from the calibration plot and expressed as $\mathrm{mg}$ Gallic Acid Equivalents (GAE) per gm sample extract (Baba et al., 2015; Shukla et al., 2009).

\section{In-vitro antimicrobial methods}

Nutrient agar media (Beef extract, Yeast extract, Peptone, Agar, pH 7.2), Liquid broth (Beef extract, Yeast extract, Peptone, pH 6.8) 
and Nutrient agar media (Malt extract, Yeast extract, Peptone, Glucose, Agar, pH 7) were prepared according to the ratio mentioned by MTCC. Sterilization is any process that eliminates all biological agents present in a specified region such as surface, biological culture, media etc. Here Autoclave was used for sterilization of all glassware and media for culture by using a pressure chamber containing saturated steam at $121^{\circ} \mathrm{C}$ for 15 20 minutes.

\section{Determination of Minimum Inhibition Concentration (MIC)}

The minimum inhibitory concentration (MIC) is the lowest concentration of an antimicrobial that will inhibit the visible growth of a microorganism after overnight incubation. MICs can be determined by agar dilution or broth micro-dilution, and they are an important parameter to confirm resistance of microorganisms to an antimicrobial agent and also to monitor the activity of new antimicrobial agents. The technique of serial dilution or stepwise dilution was used here to accurately create highly diluted solutions for these experiments resulting in generation of concentration curves with a logarithmic scale(Ira, 1995).

Minimum Inhibitory Concentration was determined using the following steps:

\section{Preparation of stock solution}

The aqueous and alcoholic extracts of research formulation stock solution were firstly prepared at $500 \mathrm{mg} / \mathrm{ml}$ using water and DMSO (Di Methyl Sulfoxide) respectively as solvent and stored as a stock solution. This stock solution of each extract was diluted in different concentrations between 50-350 $\mathrm{mg} / \mathrm{ml}$ to screen the minimum inhibition for the mentioned organism.

\section{Preparation of mother cultures}

Mother cultures were prepared using the liquid and solid media. Subcultures were made from these Mother Cultures to prepare inoculums.

\section{Preparation of inoculums}

Liquid broth was prepared maintaining $\mathrm{pH}$ for the selected strains received from MTCC in lyophilized form. Each strain was then introduced to the required nutrient broth and incubated at specific temperature and time to get inoculums of pure strain. These inoculums were further diluted to achieve colony count within the range of 300-700.

Inoculation: Inoculation is process of introducing microorganisms to the nutrient media by transfer of pure culture of each strain to respective Petri plate. $20 \mathrm{ml}$ of nutrient agar media was used to prepare Petri plates. Each plate was inoculated with particular inoculums to get colony count from 300-700(Hasan et al., 2009).

Incubation: After 18-24 hours of incubation at $25^{\circ} \mathrm{C}$, the petri plates were examined for microbial growth. MIC of the extract was taken as the lowest concentration that showed no growth.

\section{Determination of zone of inhibition of microbes}

The test for determination of the zone of inhibition was done to find out antimicrobial activities of the different extracts of research formulation following the Agar disk-diffusion method on the basis of the clear region around the paper disc saturated with an antimicrobial agent on the agar surface. The clear region is an indication of the absence or effective inhibition of microbial growth by the antimicrobial agent. 
The Whatman filter paper was used to prepare discs $6 \mathrm{~mm}$ in diameter impregnated with various diluted concentrations of aqueous and alcoholic extracts of research formulation. These discs which had been impregnated with plant extracts were placed on the surface of test organism seeded agar plates.

The standard antibiotics used were Tetracycline and Clotrimazolein the dosage of $10 \mu \mathrm{g} /$ disc for bacterial and fungal actions respectively. After incubation, the plates were examined for assessing the inhibition zone. The sensitivities of the microorganism species to the plant extracts were determined by measuring the sizes of inhibitory zones (including the diameter of disk) on the agar surface around the disks, and values $<8 \mathrm{~mm}$ were considered as not active against microorganisms. The inhibition zones were then measured and recorded. Each test was repeated three times to ensure reliability(AlBari et al., 2006).

The study showed that discs loaded with $6 \mathrm{mg}$ of research drug were not showing any active result in comparison to the standard disc in terms of the zone of inhibition. Therefore, the dosage of $8 \mathrm{mg}$ per disc has been used for all extracts and for standard for anti-bacterial and anti-fungal evaluation. The zones of growth inhibition around the disks were measured after $18-24$ hours of incubation at $37^{\circ} \mathrm{C}$ for bacteria and 48-96 hours for fungi at $28^{\circ} \mathrm{C}$.Three types of disks based on the study groups were used in this evaluation - the control or standard antibiotic disc, the negative control disc having $100 \%$ of DMSO, and the treated discs containing the research formulation.

\section{Results and Discussion}

\section{Analysis of phytochemical constituents}

Evaluation of the physical parameters of the powder of the herbal vaginal formulation indicated that while the moisture content was $8.2 \% \mathrm{w} / \mathrm{w}$, the total ash content was $12.30 \%$ $\mathrm{w} / \mathrm{w}$, the acid insoluble ash was $0.77 \% \mathrm{w} / \mathrm{w}$ and water soluble ash was $10.66 \% \mathrm{w} / \mathrm{w}$. The extractive value of aqueous extract was 1.64 $\% \mathrm{w} / \mathrm{w}$ and the extractive value of alcoholic extract was found to be $1.70 \% \mathrm{w} / \mathrm{w}$. The phytochemical constituents like alkaloids, flavonoids, tannins and carbohydrates were found to be present in the aqueous and alcohol extracts of the Research Formulation.

\section{Total phenol content (TPC)}

The total phenol content ( $\mu \mathrm{g}$ Gallic acid equivalent / $\mathrm{mg}$ of extract) was calculated from the absorbance calibration standard curve $\left(\mathrm{R}^{2}=0.997\right)$ generated with different concentrations of Gallic acid. The TPC was found to be $225.67 \mu \mathrm{g}$ Gallic acid equivalent/mg of extract in the aqueous

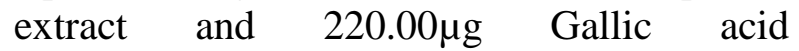
equivalent/mg of extract in alcoholic extract of the research formulation which could be directly responsible for its antimicrobial, antileucorrhoeal and astringent properties.

\section{Determination of Minimum Inhibition Concentration (MIC)}

The antimicrobial activity of aqueous and alcoholic extracts of the formulation were studied in different concentrations against four pathogenic bacterial strains, two Grampositive (Staphylococcus aureus MTCC 7405, Lactobacillus fermentum MTCC 1745) and two Gram-negative (Escherichia coli MTCC1575, Salmonella enteric MTCC 1164), and one fungal strain (Candida albicans MTCC 3958). These microbial strains have been selected on the basis of their likely application for further antibacterial and antifungal studies. The observed Minimum Inhibition Concentrations (MIC) during these antibacterial and antifungal experiments are detailed in Table 1 and shown in Figure 1. 


\section{Estimation of zone of inhibition of microbes}

The disc diffusion study of the aqueous and alcoholic extracts of the research formulation using the five bacterial and fungal strains ascertained the presence or absence of inhibition zones. The results obtained in terms of diameters of the inhibition zones of plant extracts tested for antibacterial and antifungal activity are given in Table 2 and shown in figures 2 and 3.

Antimicrobial susceptibility testing can be used for drug discovery, epidemiology and prediction of therapeutic outcome. In this review, we focused on the use of antimicrobial testing methods for in vitro investigation of extracts and pure drugs as potential antimicrobial agents. Plants and other natural sources can provide a huge range of complex and structurally diverse compounds. Recently, many researchers have focused on the investigation of plant and microbial extracts, essential oils, pure secondary metabolites and new synthesized molecules as potential antimicrobial agents because natural products are still one of the major sources of new drug molecules today (Balouiri et al., 2016).

The present study was undertaken to establish the antimicrobial efficacy of the aqueous and alcoholic extracts of the Ayurvedic vaginal formulation for the treatment of vaginitis. Leucorrhea is a one of the symptoms of vaginitis and most of its causative agents are bacterial and fungal infections. The research formulation has been newly prepared by adding equal amounts of dried parts of the stem bark of Ficus glomerata Roxb.and Symplocos racemosa Roxb. whose reported properties include astringent, haemostatic, reducing abnormal vaginal discharge and antiinflammatory substance as a single drug and in combined polyherbal form. The research formulation showed the presence of alkaloid, tannin, and flavonidic compounds in both the extracts and saponin in the aqueous extract. The total phenolic concentration was found to be marginally higher in the aqueous extract than in the alcoholic extract.

The findings of the antimicrobial activity of the aqueous and alcoholic extracts of the research formulation against the gram positive and gram negative bacterial microbes by ascertaining the MIC values detailed in Table 1 show the comparative efficacy of the two extracts as well as their antibacterial and antifungal effect upon various microbes. The results indicate that minimum inhibition concentrations were higher in case of aqueous as compared to the alcoholic extract, suggesting higher antimicrobial activity by the alcoholic extract than the aqueous extract. The MIC values were also higher in case of fungal species as compared to all the bacterial species, indicating more pronounced antibacterial action in comparison to its antifungal action by both the research drug extracts. Similarly, among the bacterial species, MIC was found to be higher in case of gram negative bacteria as compared to gram positive bacteria except Staphylococcus aureus.

The results of the estimation of diameter of the zone of inhibition created during the diskdiffusion process shown in Table 2 provide a direct indicator of the antibacterial and antifungal efficacy of the test drugs in comparison to the standard benchmarks as well as inter-se efficacies. The data in case of $6 \mathrm{mg}$ loaded disks was determined to be $<8$ $\mathrm{mm}$ in most cases and hence the same was not found to be relevant. Comparing the obtained values between the bacterial and fungal organisms, it is observed that the zone of inhibition is comparatively much smaller in case of fungal species in comparison to all the bacterial species, suggesting higher 
antibacterial action than anti-fungal action by all extracts. Between the two types of bacteria, the zone of inhibition was found to be larger in case of Gram positive species in comparison to the Gram negative species, implying stronger antibacterial effect upon Gram positive bacteria than Gram negative bacteria. The alcoholic extract exhibited higher zones of inhibition than the aqueous extract for all types of antimicrobial categories during this study. Similarly, the antimicrobial efficacy of alcoholic extract using $8 \mathrm{mg}$ per disk drug dosage was a little lower but comparable to the effect of the standard drugs at $10 \mu \mathrm{g} / \mathrm{disc}$ level. The antimicrobial efficacy of the research formulation was higher in case of the alcoholic extract than the aqueous extract in both the methods used during this study. Both the alcoholic and aqueous extracts exhibited a higher antibacterial action when compared with its antifungal effect. Between the two types of bacterial species tested during this experiment, the research drug had a definitely higher impact in case of Gram positive bacteria in comparison to the Gram negative strains.

Table.1 Minimum Inhibitory Concentrations during antibacterial and antifungal studies

\begin{tabular}{|l|c|c|}
\hline Pathogen & $\begin{array}{c}\text { MIC using aqueous } \\
\text { extract (mg/ml) }\end{array}$ & $\begin{array}{c}\text { MIC using alcoholic } \\
\text { extract (mg/ml) }\end{array}$ \\
\hline Staphylococcus aureus & $10.00 \pm 0.63$ & $5.00 \pm 0.10$ \\
\hline Lactobacillus fermentum & $6.25 \pm 0.26$ & $3.75 \pm 0.15$ \\
\hline Escherichia coli & $7.50 \pm 0.40$ & $5.00 \pm 0.18$ \\
\hline Salmonella enterica & $7.50 \pm 0.23$ & $6.25 \pm 0.23$ \\
\hline Candida albicans & $17.50 \pm 0.34$ & $10.00 \pm 0.58$ \\
\hline
\end{tabular}

Values represented as Mean \pm SEM

Table.2 Diameters of zone of inhibition during disk diffusion study

\begin{tabular}{|c|c|c|c|c|c|c|}
\hline \multicolumn{2}{|c|}{ Test organisms } & \multirow{2}{*}{$\begin{array}{l}\begin{array}{l}\text { Aqueous } \\
\text { Extract @ } \\
\text { 6mg/disc }\end{array} \\
8 \pm 0.41\end{array}$} & \multirow{2}{*}{$\begin{array}{l}\text { Aqueous } \\
\text { Extract } \\
\text { @8mg/disc } \\
20 \pm 0.88\end{array}$} & \multirow{2}{*}{$\begin{array}{l}\text { Alcoholic } \\
\text { Extract } \\
@ 8 m g / \text { dis } \\
\text { c } \\
24 \pm 0.44\end{array}$} & \multirow{2}{*}{$\begin{array}{l}\text { Standard } \\
\text { Drug } \\
\text { Tetracyclin } \\
\text { e 10 } \mu \text { g/disc } \\
32 \pm 0.5\end{array}$} & \multirow{2}{*}{ 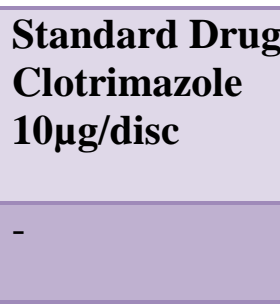 } \\
\hline$=: \stackrel{0}{=}$ & $\begin{array}{l}\text { Staphylococcus } \\
\text { aureus }\end{array}$ & & & & & \\
\hline है & $\begin{array}{l}\text { Lactobacillus } \\
\text { fermentum }\end{array}$ & $6 \pm 1.2$ & $21 \pm 0.88$ & $23 \pm 0.88$ & $32 \pm 0.7$ & - \\
\hline \multirow{2}{*}{ 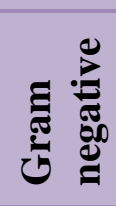 } & Escherichia coli & $5 \pm 0.22$ & $17 \pm 1.24$ & $19 \pm 1.2$ & $31 \pm 0.3$ & - \\
\hline & $\begin{array}{l}\text { Salmonella } \\
\text { enterica }\end{array}$ & $5.5 \pm 0.8$ & $19 \pm 1.4$ & $21 \pm 0.3$ & $30 \pm 0.51$ & - \\
\hline$\stackrel{60}{\Xi}^{E}$ & $\begin{array}{l}\text { Candida } \\
\text { albicans }\end{array}$ & - & $12 \pm 0.8$ & $14 \pm 0.8$ & - & $20 \pm 0.22$ \\
\hline
\end{tabular}

Values represented as Mean \pm SEM 
Fig.1 Graphical representation of MIC for A: Staphylococcus aureus, B: Lactobacillus fermentum, C: Escherichia coli, D: Salmonella enterica and E: Candida albicans. (Blue bar denotes Aqueous extract while red bar denotes Alcoholic extract)

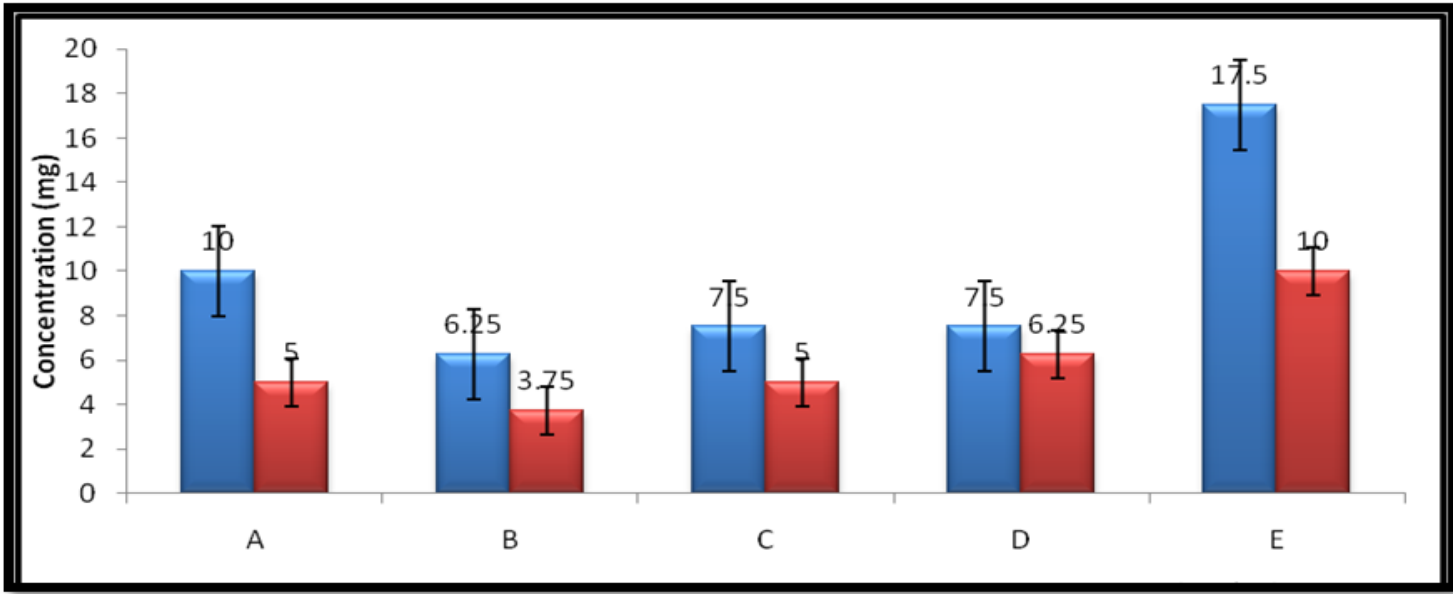

Fig.2 Graphical presentation of Zone of inhibition for Bacteria (A: Staphylococcus aureus, B: Lactobacillus fermentum, C: Escherichia coli, D: Salmonella enterica)

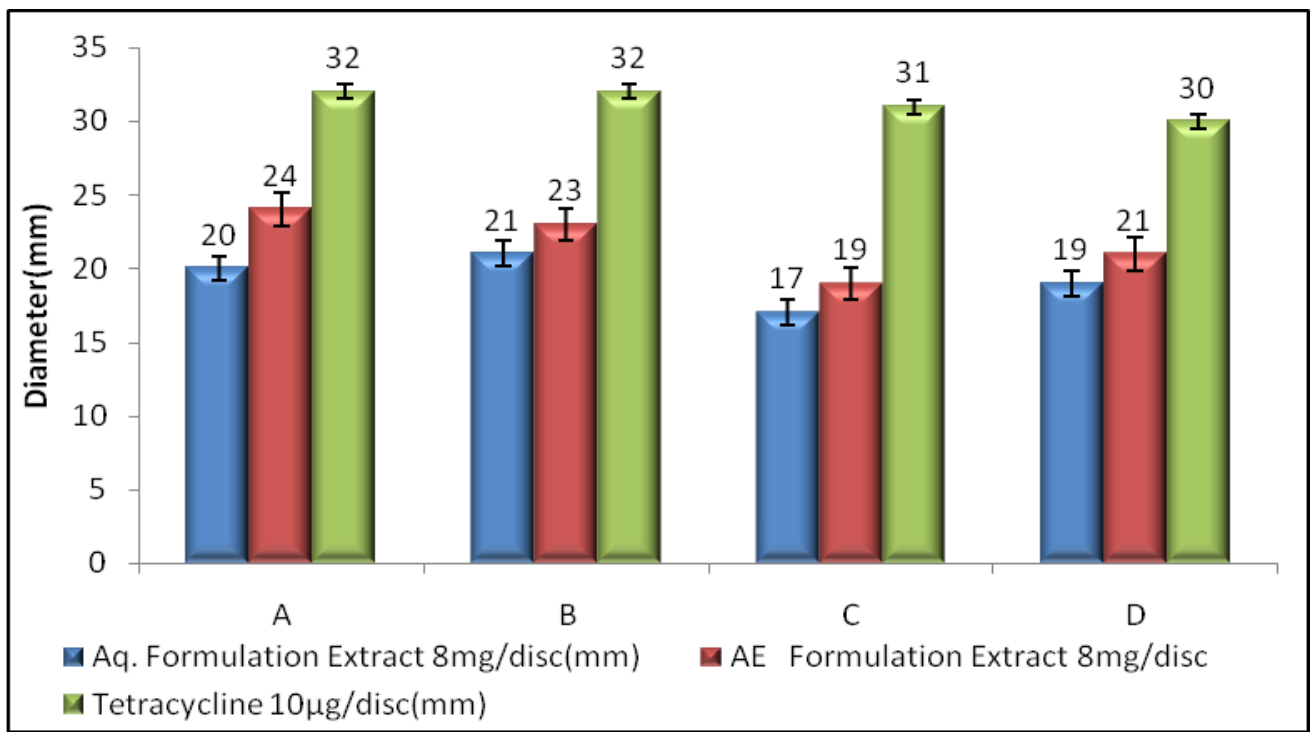

Fig.3 Graphical presentation of Zone of inhibition for Candida albicans

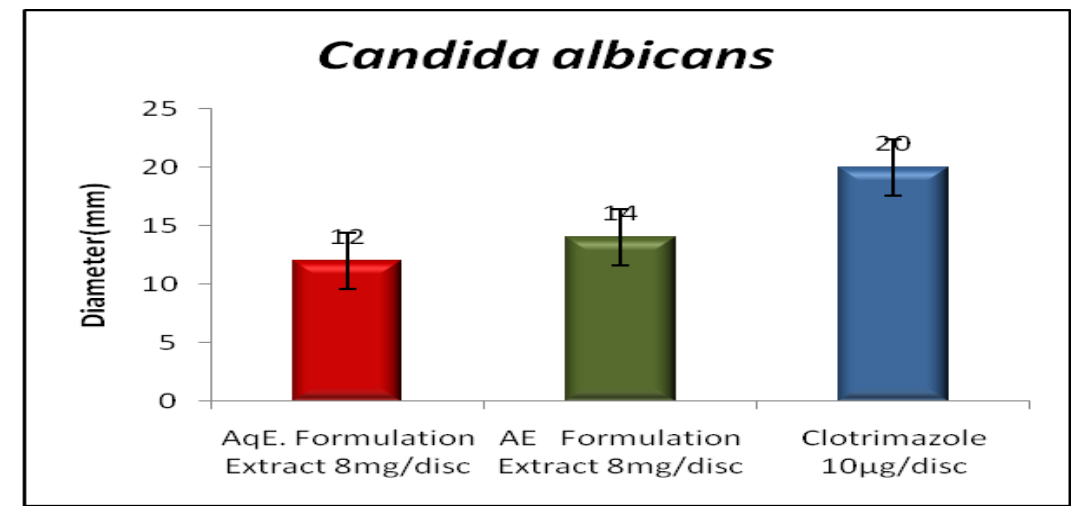


The overall antimicrobial effect of the research extracts was significant and comparable but a little lower when compared to the standard drugs. Hence, both the extracts could be an effective herbal vaginal formulation for the treatment of bacterial and fungal types of vaginitis.

In conclusion, the evaluation of antimicrobial activity of aqueous and alcoholic extracts of the Ayurvedic vaginal formulation having equal amounts of powder of stem barks of Symplocos racemosa Roxb. and Ficus glomerata Roxb. against the five pathogen microbes by using the minimum inhibition concentration and the zone of inhibition methods showed significant antibacterial and antifungal properties. These therapeutic activities were found more pronounced in the alcoholic extract as compared to the aqueous extract. The research formulation showed higher antibacterial properties as compared to the antifungal properties. In terms of antibacterial action, the research formulation had a higher effect on gram positive bacteria as compared to the gram negative bacteria. This newly prepared Ayurvedic Formulation shows good potential for treatment of vaginitis on the basis of findings of this study while further research is required for standardization of the Ayurvedic vaginal tablet.

\section{Acknowledgements}

This research work was supported by grants from the Indian Council of Medical Research, Government of India (Sanction Letter No. 59/1/2011/BMS/TRM dated 12.12.2013) and the authors are grateful for this support. We are thankful to Dr. Tapan Seal, Senior Scientific Officer, Botanical survey of India, Howrah, Kolkata for identification and other scientific help during the research work.

\section{References}

Ahmad, V.U., Abbasi, M.A., Hussain, H., Akhtar, M.N., Farooq, U., Fatima, N. Choudhary, M.I. 2003. Phenolic glycosides from Symplocos racemosa: natural inhibitors of phosphodiesterase I. Phytochemistry, 63(2): 217-220.

Akinpelu, D.A. and T.M. Onakoyo, 2006. Antimicrobial activities of medicinal plants used in folklore remedies in Southwestern. Afr. J. Biotech., 5(11): 1078-1081.

Al-Bari, M.A.A., Sayeed, M.A. Rahman, M.S. 2006. Characterization and antimicrobial activities of a phenolic acid derivative produced by Streptomyces Bangladeshiensis, a novel species collected in Bangladesh, Res. J. Med. and Med. Sci., 1: 77-81.

Baba, S.A. Malik, S.A. 2015. Determination of total phenolic and flavonoid content, antimicrobial and antioxidant activity of a root extract of Arisaema jacquemontii. Journal of Taibah University for Science, 9: 449-454.

Balouiri, M., Sadiki, M. Ibnsouda, S. K. 2016. Methods for in-vitro evaluating antimicrobial activity: A review, Journal of Pharmaceutical analysis, 6(2): 71-79.

Bhalodia, N. R. Shukla, V. J. 2011. Antibacterial and antifungal activities from leaf extracts of Cassia fistula: An ethnomedicinal plant, J Adv Pharm Technol Res, 2(2): 104-109.

Devmurari. V.P. 2010. Antibacterial Evaluation and Phytochemical Screening of Symplocos racemosa Roxb, International Journal of Pharm Tech Research, 2(2): 1359-1363.

Doughari, J.H., El-mahmood, A.M. Tyoyina, I. 2008. Antimicrobial activity of leaf extracts of Senna obtusifolia (L.), Afr. J. Pharm. Pharmacol., 2(1): 07-13. 
Farnsworth, N.R., Akerele, O., Bingel, A.S., Soejarto, D.D. Guo, Z. 1985. Medicinal plants in therapy. Bull. World Health Organ. 63: 965-981.

Furniss, B.S., Hannaford, A.J. Smith, P.W.G. Tatchell AR. 1989.Vogel's Textbook of Practical Organic Chemistry, 5th Edition; Addison Wesley Longman Inc. 1989, 1205.

Harborne, J.B. 1984. Phytochemical Methods: A guide to Modern Technique of Plant Analysis, $2^{\text {nd }}$ edition, Chapmann and Hall: London.

Hasan, M. F., Das, R., Khan, A., Hossain, M.S. Rahman, M. 2009. The Determination of Antibacterial and Antifungal Activities of Polygonum hydropiper (L.) Root Extract, Advances in Biological Research, 3 (1-2): 53-56.

Hegde, M.V., Patil, S. Bhalerao, S. A. 2008. Philosophy for integration of ayurveda with modern medicine: A biochemist's perspective. Curr. Sci, 95: 721-722.

Ira R. 1995. Bacteriology, Standard Operative procedure manual for microbiology laboratories, National Institute of Biologicals, 73-97.

Jain, S.C., Singh, R. Jain, R. 2008. Antimicrobial and antioxidant potentials of Verbesina encelioides (Cav.) Benth. and Hook. Fil ex Gray, Res. J. Med. Plant, 2(2): 61-65.

Joshi, U. Mohini, U. 2008. Evaluation of antioxidant activity of aqueous extract bark of Ficus glomerata, Research Journal of Pharmacy and Technology, 1(4): 537-538.
Sharma, P. V. 1995. Introduction to Dravyaguna (Indian Pharmacology), vol. 2; Chaukhamba Orientalia, Varanasi, India, 616, 666.

Sharma, P.C, Yelne, M. B. Dennis, T. J. 2001. Database on medicinal plants used in Ayurveda, Central Council for Research in Ayurveda \& Siddha, Department of Indian system of medicine, Govt. of India, New Delhi, vol. 3, 76-87, 166.

Shastri, S. N. 1988. Charak Samhita (Chikitsa Sthanam), Chapter 3; Chaukhamba Bharati Academy, Varanasi, India, 47.

Shukla, S., Mehta, A., Bajpai, K.V. Shukla, S. 2009. In vitro antioxidant activity and total phenolic content of ethanolic leaf extract of Stevia rebaudiana Bert. Food Chem. Toxicol. 47: 2338-2343.

Wang, S. Y. Jiao, H. 2000. Scavenging capacity of berry crops on superoxide radicals, hydrogen peroxide, hydroxyl radicals, and singlet oxygen. J. Agric. Food. Chem. 48(11): 5677-5684.

Wei, W., Xue-Ke, Z., Nan, W., Yu-jie, F. Yuan gang, Z. 2006. Antimicrobial activities of essential oil from Artemisi aeargyi leaves. J. Forestry Res., 17(4): 332-334.

Živković J, Zeković Z, Mujić I, Vidović S, Cvetković D, Lepojević Ž, Nikolić G, Trutić N. 2010. Scavenging Capacity of Superoxide Radical and Screening of Antimicrobial Activity of Castanea sativa Mill. Extracts. Czech. J. Food. $\begin{array}{llll}\text { Sci. } & 28 & \text { (1): }\end{array}$

\section{How to cite this article:}

Mradu Gupta, Simit Kumar, Benoy Brata Bhowmik, Nandita Karmakar and Saswati Sasmal. 2019. Comparative Antimicrobial Efficacy Evaluation of Aqueous and Alcoholic Extracts of Ayurvedic Vaginal Formulation for Treatment of Vaginitis. Int.J.Curr.Microbiol.App.Sci. 8(04): 635-645. doi: https://doi.org/10.20546/ijcmas.2019.804.069 